\title{
A Case Report: Subglottic Stenosis Observed in Early Postoperative Period
}

\author{
Ibrahim Mungan*, Sema Turan, Hayriye Cankar Dal, Çilem Bayındır Dicle, Sema Sarı and Büşra Tezcan \\ Department of Intensive Care Unit, Turkey Advanced Speciality Education and Research Hospital, Turkey
}

*Corresponding author: VIbrahim Mungan, MD, Department of Intensive Care Unit, Turkey Advanced Speciality Education and Research Hospital, Altındag/Ankara, Turkey

Submission: June 18, 2018; Published: August 20, 2018

\section{Background}

Subglottic stenosis (SGS) is a rare disorder which involves a partial or complete narrowing of the airway affecting subglottis (area between the glottis and the cricoid cartilage). It influences airflow sufficiency and provokes prominent respiratory complications [1]. Congenital and idiopathic forms of the SGS are rare and it is usually seen as an iatrogenic complication after prolonged endotracheal intubation or long-term tracheostomy. However, short-dated endotracheal intubation may also cause SGS, and mucosal ischemia is accused for granulation tissue formation and healing with constriction [2].

The incidence of post-intubation SGS was reported as high as $19 \%$ in the literature while basic preclusive measures like reducing cuff pressure with high volume balloons may prevent its occurrence [3]. In SGS, the clinical manifestation is linked directly to the degree of the stenosis and the sufficiency of airflow. Mild stenosis may be confused with laryngospasm whereas reduction in diameter of the airway more than $75 \%$ (as seen in most cases) presented itself with severe respiratory distress [4]. The patients presenting with increasing respiratory discomfort are diagnosed by radiological examination and indirect/direct laryngoscopy. In some studies, it is emphasized that early recognition and management of these lesions in the early stage lead to favourable long-term outcomes [1].

Surgical treatment options include open or endoscopic neck surgery and tracheotomy while endoscopic approaches are excision of the stenotic segment, bronchoscopic dilatation, and tracheal stenting [5]. Although, surgery is considered as the best treatment choice, in cases assumed unfit for surgery endoscopic interventions are reasonable options [3]. In this article, we present a case of subglottic stenosis occurred in the early postoperative period.

\section{Case Report}

A 56-year-old woman was diagnosed as ischemic heart disease(IHD)-and admitted to the cardiovascular surgery department. The cardiac catheterization revealed coronary artery disease-(CAD)and she was prepared for surgery. A transthoracic echocardiogram (TTE) was done preoperatively and ejection fraction was found $55 \%$. In the preoperative evaluation of the patient, no pathology related to the respiratory tract was detected. She underwent coronary artery bypass grafting (CABG) successfully and transferred to the intensive care unit. 8 hours after the surgery, she was extubated and 16 hours later shifted to the ward.
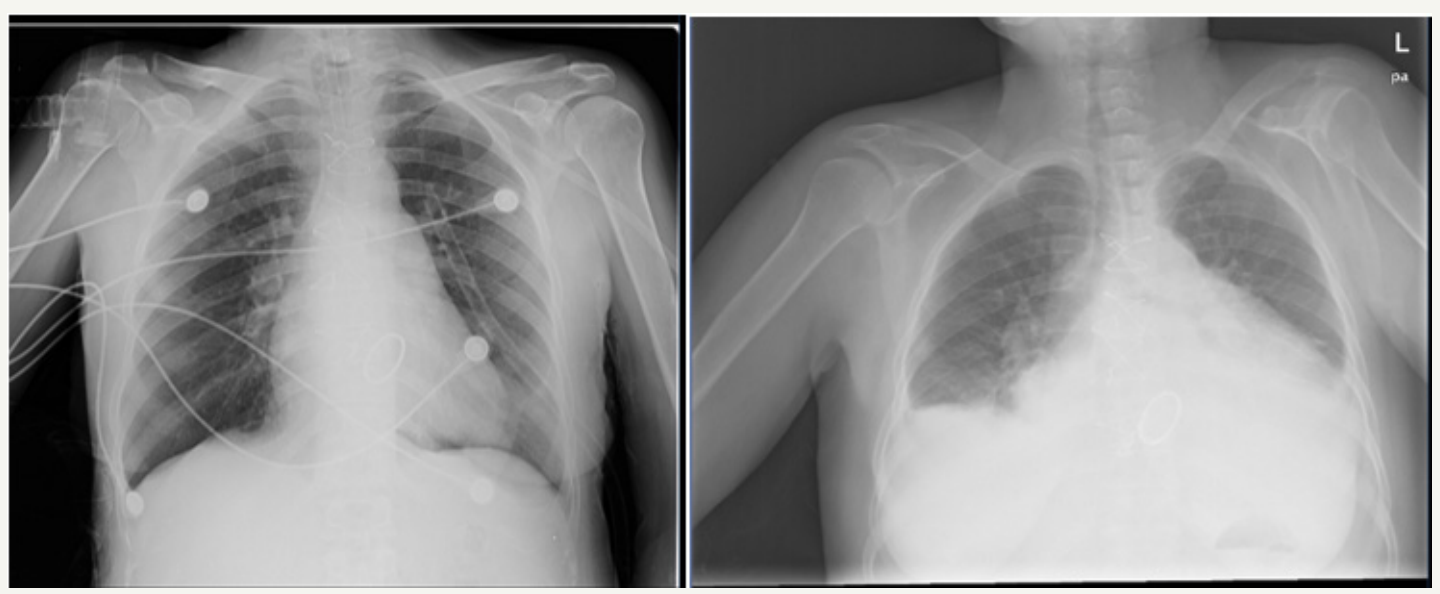

Figure 1: Anterior-posterior chest X-ray revealed narrowing of the subglottis level (on the right side) -that was not detected preoperatively(on the left side). 
The postoperative period was eventless but on the $5^{\text {th }}$ day postoperatively, progressive dyspnea and acute stridor necessitated emergency intubation. On direct laryngoscopy, stenosis below the vocal cords was detected and she was intubated with $5 \mathrm{~mm}$ internal diameter, non-cuffed, endotrecheal tube (ETT). Medical treatment with dexamethasone and bronchodilators was initiated as well but this did not produce any improvement. Anterior-posterior chest X-ray revealed narrowing of the subglottis level-that was not detected preoperatively- (Figure 1) and bronchoscopic dilatation was planned. Unfortunately the patient suffered incessant ventricular tachycardia and then asystolic cardiac arrest. Despite all interventions the patient died 4 hours later.

\section{Discussion}

The narrowest part of the airway is the subglottic area and may be injured after endotracheal intubation. Iatrogenic SGS was mainly related to mucosal damage and ischemia induced by the rigid wall of the ETT, cuff pressure and inflammatory response. Airway trauma, inhalation burns and irradiation are the other acquired causes of SGS [6]. The incidence of acquired tracheal stenosis was reduced by development of high-volume, low-pressure ETT cuffs while comorbidities like myocardial infarction and congestive heart failure enhances mucosal damage [7]. Our case had a history of CAD and IHD as a predisposing factor without any respiratory disorder.

The narrowing less than $50 \%$ of the airway causes no symptoms generally whereas moderate stenosis (51\%-70\% obstruction) and severe stenosis ( $>71 \%$ obstruction) cause progressive dyspnea even at rest by reducing pressure exerted [8]. Most patients with SGS have presented with mild to moderate severity of the narrowing. The overall incidence of SGS is decreasing after new technologies and only $2 \%$ of the patients are symptomatic. Generally prolonged intubation is accused for mucosal injury and tracheal stenosis is rare when intubation was $<1$ week [7]. In our case the patient developed SGS after intubation of $<24$ hours and this is a rare condition. SGS, as a complication, can be avoided by obvious and simple precautions like the appraisal and limitation of the cuff pressure and abstinence of recurrent intubations [4].

There are less invasive alternative treatment modalities for SGS but surgical resection is a primary therapeutic option [6]. In the case of the index patient bronchoscopic evaluation and dilatation was planned as an initial treatment before definitive surgical correction but the patient was ceased due to cardiac complications.

In conclusion, SGS should be suspected even in early postoperative period and in short term intubation cases. Prompted diagnosis and effective treatment are a must in an emergent manner. Radiologic and direct-indirect laryngoscopy findings show narrowing of the airway and difficult intubation preparation with different ETT sizes should be done [9].

\section{Informed Consent}

Written informed consent was obtained from the patient and relatives for publication of this manuscript and any accompanying images.

\section{References}

1. Raman T, Chatterjee K, Alzghoul BN, Innabi AA, Tulunay O, et al. (2017) A bronchoscopic approach to benign subglottic stenosis. SAGE Open Med Case Rep 5: 2050313X17713151.

2. Allred C, Queimado L, Krempl G (2013) Case report: Postintubation tracheal stenosis: Case report and review of current management. Journal of Case Reports in Medicine 2(2013): 3.

3. Prasad KT, Dhooria S, Sehgal IS, Aggarwal AN, Agarwal R (2016) Complete subglottic tracheal stenosis managed with rigid bronchoscopy and T-tube placement. Lung India 33(6): 661-663.

4. Karapantzos I, Karapantzou C, Zarogoulidis P, Tsakiridis K, Charalampidis C (2016) Benign tracheal stenosis a case report and up to date management. Annals of Translational Medicine 4(22): 451.

5. Feinstein AJ, Goel A, Raghavan G, Long J, Chhetri DK, et al. (2017) Endoscopic management of subglottic stenosis. JAMA Otolaryngol Head Neck Surg 143(5): 500-505.

6. D'Andrilli A, Venuta F, Rendina EA (2016) Subglottic tracheal stenosis. J Thorac Dis 8(Suppl 2): S140-S147.

7. Barreiro TJ, Ghattas C, Valino CA (2013) Iatrogenic tracheal stenosis presenting as persistent asthma. Respir Care 58(9): e107-e110.

8. Oh SK, Park KN, Lee SW (2014) Long-term results of endoscopic dilatation for tracheal and subglottic stenosis. Clin Exp Otorhinolaryngol $7(4)$ : 324-328.

9. Cook TM, MacDougall DSR (2012) Complications and failure of airway management. Br J Anaesth 109( Suppl 1): i68-i85.
Creative Commons Attribution 4.0 International License

For possible submissions Click Here

\section{Submit Article}

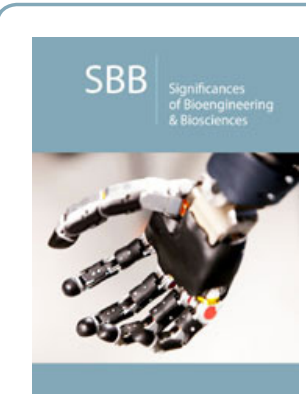

Significances of Bioengineering \& Biosciences

\section{Benefits of Publishing with us}

- High-level peer review and editorial services

- Freely accessible online immediately upon publication

- Authors retain the copyright to their work

- Licensing it under a Creative Commons license

- Visibility through different online platforms 